doi: 10.26529/cepsj.497

\title{
Elgrid Messner, Daniela Worek and Mojca Peček (Eds), Teacher Education for Multilingual and Multicultural Settings, Graz: Leykam, 2016; 199 pp.: ISBN 978-3- 7011-0361-4
}

Reviewed by KARMEN MLINAR ${ }^{1}$

The growth of migrations that are changing the face of Europe brings various challenges that society, and particularly educational institutions, are able to confront to varying degrees. Today, it is clearer than ever that existing integration (or segregation) policies are insufficient, and that these policies cannot or do not know how to properly deal with the increasing diversity of society and the diversity/otherness of its new members. The role of educational institutions at all levels is therefore all the more important. It is at these institutions that future generations of individuals

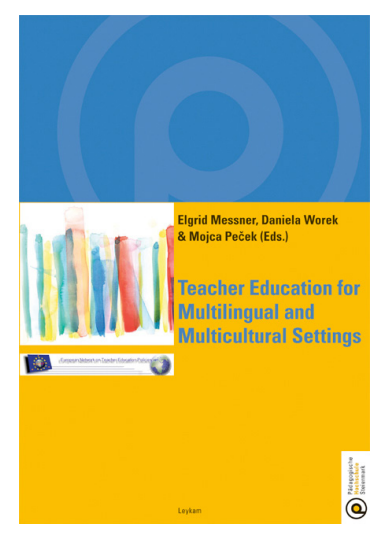
are formed and educated, individuals who will have the opportunity to build a society in which everybody is respected and accepted despite and because of their otherness, and where the differences are understood as new values, rather than contributing to a closed society full of fears, prejudice and hate.

The scientific monograph Teacher Education for Multilingual and Multicultural Settings, edited by Elgrid Messner, Daniela Worek and Mojca Peček, and published under the auspices of the European Network of Teacher Education Policies, offers the reader critical analyses and answers, but also opens numerous important issues and topical dilemmas related to the multicultural environment we face today. The volume consists of an Introduction, four thematic chapters, and Conclusions and Recommendations.

In the Introduction, the editors present the development of the monograph, which began in 2015 when, at the autumn ENTEP conference in Ljubljana, Slovenia, the debate was focused on the dilemma of how to prepare teachers for teaching in diverse settings. In the Introduction, the content of the monograph is briefly presented. The second paper of the Introduction, written by Ursula Uzerli, addresses the need to provide teachers with intercultural

1 University of Ljubljana, Faculty of Education, Slovenia; karmen.mlinar@pef.uni-lj.si. 
awareness and competences, including the ability to be self-reflective. As the author emphasises, it is crucial that university programmes, especially in the initial phase of teacher education, prepare teachers for the challenges of culturally diverse classes. The article briefly presents the possibilities that are already offered by some European countries and describes some examples of specific curricula in Initial Teacher Education and Continuous Professional Development for (future) teachers in diverse settings.

Chapter I (Theoretical Considerations and Practical Insights) begins with Robi Krofličs article setting out the shortcomings of Rawl's concept of distributive justice, and emphasising the need to focus on the recognition and representation of marginalised pupils/students. For the author, one of the most important pedagogical questions in multicultural education is how to change our attitudes towards the other as different. One of the ways to achieve this goal is the inductive educational approach, and one of the tools is education through artistic experience. The author presents some examples of implementing multicultural education with children/students and the importance of the teacher developing a proper attitude towards the otherness of the other. The next article, written by Sonja Rutar, discusses the pathways to achieving quality in education. In the first part, the author explains the meaning and importance of quality in education and distinguishes it from effectiveness. She then explains how to achieve quality through positive recognition, literacy development and child participation. In her article, Nada Turnšek presents the theoretical foundations of three approaches to diversity, equity and social inclusion: the multicultural, the intercultural and the anti-bias approach. The author starts by presenting the development of the concepts, and continues by presenting and critically evaluating the practical applications of each of them in some Slovenian preschool institutions. She points out the importance of the antidiscrimination and diversity training at the Faculty of Education in Ljubljana, as a programme that equips preschool teachers with competences that enable the application of the anti-bias approach. For the author, this approach, unlike the other two approaches, is related not only to activities for children, but also to the creation of a group ethics and ethos, characterised by equality and an anti-racist environment. In their article, Sunčica Macura and Bojana Dimitrijević analyse the position of the inclusive education of Roma children in preservice teacher education programmes in Serbia. Many teacher educators fail to face the topic of social exclusion and therefore contribute to maintaining the status quo in society; on the other hand, as victims of their own stereotypes, they are unable to prepare student teachers to teach and educate in a culturally diverse environment. One of the main reasons for this is the restrictive concept of inclusive 
education, which is still generally connected with pupils with special needs and not with pupils who need additional support. The authors then offer an interesting insight into two models of practical activities that prepare teachers for multicultural settings with Roma pupils in Serbia: Intercultural Experiential Learning and Cross-Cultural Field Experience, which prepare and motivate student teachers to work with Roma children. As the authors point out, there is a need to continue to develop models and practices that can prepare teachers for better work in diverse environments. The last article of the first chapter, written by Mihaela-Monica Stîngu, Elena Marin and Georgeta Ion, discusses the question of facing diversity issues in the context of higher education. As the authors stress, in the context of higher education, equity - a key concept in education - means to enable all students to exploit their potential by creating a system that "creates opportunities for equal access and success among all vulnerable students" (p. 76). In the article, the authors analyse the status of equity in higher education in Romania through policy and practice, with a special emphasis on teacher education programmes. The status of intercultural education in such teacher training programmes should change, because, as the authors stress, is not represented enough.

Chapter II (European Perspectives and Initiatives) begins with Francesca Caena's article presenting the multilingual and intercultural agenda in the European context, highlighting European language teacher education. The author presents the Italian context, where non-Italian students need special support in education; to make this possible, however, teachers need support, too, especially related to lifelong learning, which includes reform of the teaching profession. Klaus-Börge Boeckmann begins his article with a presentation of Council of Europe and European Union documents on teaching in a culturally and linguistically diverse context. As the author determines, all of the documents share the common finding that "all teachers/educators in the system need initial, pre-service and in-service training especially designed to enable them to cope with linguistic and cultural diversity" (p. 105). In the second part of the article, the author presents two Austrian application projects: Majority Language Instruction as a basis for Plurilingual Education and the Framework of Reference for Pluralistic Approaches to Languages and Cultures; and an initiative called Autobiography of Intercultural Encounters. Even if there is widespread agreement on the measures that should be taken in relation to multilingualism, multiculturalism and migration in school systems, teachers themselves, and even teacher educators, are not clear about which tools to use in the classroom. The author therefore suggests the development of materials on the European level, which can then be adapted on the local level. 
Chapter III (Policy Measures) begins with an article by Vlatka Domović and Vlasta Vizek Vidović. The authors present the Croatian context of multicultural and intercultural education and analyse the policy framework for minority and multicultural and intercultural education by pointing out the problems faced by schools and related to teacher preparation to teach in diverse contexts. The Croatian authors again find that intercultural education in initial teacher training is recognised as important at the policy level, but is not compulsory in curricula. As the authors determine, teachers are not sufficiently prepared and equipped with competences to teach in culturally diverse contexts. The authors therefore stress the importance of the development of intercultural competences during initial teacher education and continuous professional development. In the next article, Larisa Kasumagić Kafedžić presents a brief overview of postconflict education in Bosnia and Herzegovina, where post-war society is very fragmented, opening the question of whether the education system is capable of taking responsibility for promoting the values of non-discrimination and peace. Despite there being more questions than answers, the author unequivocally addresses the importance of the training and continuing professional development of teachers, oriented to the multicultural and intercultural context. The third article of the chapter, which is the work of Jean-Jacques Weber, treats the case of Luxemburg. The author first presents the complex language situation in Luxemburg - where German is the main language, followed by Luxembourgish and French - and the implications of this for the education system. Given that the home language of the majority of pupils in many primary schools is one of the Romance languages, and due to the historical context of the trilingual system, the question arises as to whether the language-in-education policy should be more open and flexible, which would also have repercussions for teacher education and the establishment of linguistic tolerance as a key value among teachers. The last article in this chapter is written by Dagmar Gilly, Daniela Gronold and Barbara Schrammel-Leber. The authors present the activities and projects of the Austrian Federal Centre for Interculturality, Migration and Multilingualism, which supports the University College of Teacher Education "in the process of opening up to diversity" (p. 146). The Centre has an important role in cooperation and quality development related to interculturality, migration and multiculturalism in teacher education and training in Austria.

Chapter IV (Mobility) begins with an article by Haiko Vogl, Goerg Krammer, Susanne Linhofer and Regina Weitlaner that systematically describes and analyses the University College of Teacher Education Styria's Erasmus+ course "International Teacher Competences". The programme provides students with a variety of learning opportunities that shape their personalities, 
resulting in greater employability of prospective teachers. The authors also present a qualitative content analysis of the merits of the course through the Big Five factor domains (openness, emotional stability, conscientiousness, extraversion, agreeableness). The results show that the course not only provides all of the benefits expected in a mobility programme, but also enhances the students' future teaching career. In the second article, Daniela Elsner and Daniela Worek discuss the opportunities for and obstacles to mobility in German Teacher Education Programmes from the point of view of the professionalisation of teachers in the context of diversity. The authors point out the need for the international experience gained by students studying abroad, as well as the benefits of such experience, but note that the quantity and quality of measures taken by universities are very different. It is necessary to give credit for "international activities, transitional education or inward and outward mobility" (p. 175), in order to integrate globally themed activities in teacher education, to include more international students in teacher programmes, etc. As the authors point out, there is therefore a need to rethink the current education system.

In Conclusions and Recommendations, Mojca Peček first analyses the conceptual framework for teacher education and stresses that different countries have different explanations for "cultural diversity", despite the fact that the goal of most countries is to build a society in which all cultures are equally respected and included. She points out that there are differences even in the understanding of teacher competences for managing diversity in the classroom, but that most researchers nonetheless emphasise the importance of the cognitive, pragmatic and affective dimensions of intercultural competences. Next she turns to the organisational aspects of teacher education. Despite the fact that, on the European level, intercultural competences of teachers are recognised as crucial for work in linguistically and culturally heterogeneous classrooms, studies show that the development of these competences at the national level is not always included in teacher education programmes. It is therefore very important, as Mojca Peček explains, that European guidelines are implemented in teaching practice. Finally, the author stresses that the knowledge gained during the study process is not enough to guarantee an inclusive environment and to improve school practice; it is important that future teachers work on themselves, that they confront themselves with their own behaviours and practices. In this regard, in the last part of the volume, the author lists a series of proposals on how to improve teaching programmes for teachers in order to enable successful work in multicultural and multilingual settings.

The volume certainly provides an interesting and systematic insight into European theory and practice related to multicultural and multilingual 
settings, and offers a series of proposals on how to improve teacher education programmes. There is a need for student and professional teachers to gain intercultural competences and other abilities on the cognitive and personal level that are essential for work in inclusive environments. Today, it is essential to discuss examples of good practices and to expose incorrect practices; at the same time, there is a need to present suggestions to complement, upgrade or improve such practices. Multiculturalism is no longer a question, nor is it a matter of time; it is a fact that influences and will continue to influence European society. The question is whether this society will be one characterised by intercultural dialogue, coexistence and respect, or a society divided into "us" and "them". The role of education institutions is crucial in facilitating the development of the first option. These institutions will teach pupils how to confront their own fears, prejudices and stereotypes, and how to live in mutual respect and appreciation. To make this possible, it is essential that teachers develop adequate competences and personal qualities to work in an intercultural way. We believe that the present volume is an important source of knowledge and ideas, providing a basis for the further personal development, work and research of student and professional teachers who already work or will work in multicultural and multilingual settings, as well as being an important resource for planners of teacher education programmes. 